\title{
Convective instabilities in horizontally propagating vertical chemical fronts
}

\author{
Gábor Schuszter, Tamara Tóth, Dezső Horváth, and Ágota Tóth* \\ Department of Physical Chemistry, University of Szeged, \\ Rerrich Béla tér 1., Szeged, H-6720, Hungary
}

(Dated: December 18, 2008)

\begin{abstract}
Effect of convection on horizontally propagating fronts arising in the acid-catalyzed reaction of chlorite and tetrathionate ions is investigated experimentally in vertically oriented narrow reaction vessels of various heights. A stable finger develops which can be characterized by its mixing length defined as the standard deviation of the average front profile. The mixing length scales with the height of the reaction vessel and the scaling law has been determined for three different chemical compositions.
\end{abstract}

PACS numbers: $89.75 . \mathrm{Kd}, 47.20 . \mathrm{Bp}, 47.54 .-\mathrm{r}, 47.70 . \mathrm{Fw}$

${ }^{*}$ E-mail : atoth@chem.u-szeged.hu 


\section{INTRODUCTION}

One of the simplest patterns arising from the interaction of an autocatalytic reaction and transport processes is a propagating reaction-diffusion front[1]. In autocatalytic chemical reactions the reactants are converted into products at the front and the diffusion of the autocatalyst molecules drives the front into the fresh reactant zone. If the density changes during the reaction, the buoyant forces may enhance the mixing of the reactants and the products, hence affect pattern formation[1, 2].

Both experimental[3-6] and numerical studies [7-9] have been carried out in order to quantitatively describe the effect of convection on vertically propagating planar reaction fronts in wide and narrow vessels, so called Hele-Shaw cells[10]. From microscopic perturbations cellular patterns evolve which are characterized by dispersion curves where the growth rate is given as a function of its wave number. The positive growth rate expresses that the mode is convectively unstable and hence its amplitude increases exponentially with time, while the negative value represents a convectively stable mode, the contribution of which to the evolving pattern decreases with time. The average wave length of the initial cellular pattern therefore lies in the vicinity of that of the most unstable mode. In a narrower reaction vessel the merging of the initial cells leads to a stable single finger propagating at constant velocity[11, 12] which may be quantitatively described by the mixing length and the temporal average of the stable front profiles. It has been predicted numerically[13] and proved experimentally[14] that the mixing length scales linearly with the width of the container.

One expects that vertically oriented reaction fronts propagating horizontally in moderately high and narrow reaction vessels may be affected by convection as well, since a vertical interface separating two solutions of different density is hydrodynamically unstable as the denser fluid tends to sink under the other giving rise to a large convection roll. As the gravitational force is now perpendicular to the direction of front propagation, a substantially different structure is anticipated to evolve from the microscopic perturbations compared to horizontal fronts propagating vertically. Rongy et al. have analyzed numerically the buoyancy-driven convection in horizontal solution layers[15]. They have found that if the products are denser than the reactants, the products slip under the reactants and a vortex rotating counterclockwise evolves when the front propagates from left to right. They have 
also studied the influence of the height of the layer and found that if it is increased, the mixing length increases nonlinearly, as a square function with the height of the solution layer.

The chlorite oxidation of tetrathionate is an acid-catalyzed reaction in slight chlorite excess $[16,17]$

$$
7 \mathrm{ClO}_{2}^{-}+2 \mathrm{~S}_{4} \mathrm{O}_{6}^{2-}+6 \mathrm{H}_{2} \mathrm{O}=7 \mathrm{Cl}^{-}+8 \mathrm{SO}_{4}^{2-}+12 \mathrm{H}^{+}
$$

The density increases in the course of the reaction leading to convectively stable upward and unstable downward propagating fronts in thin solution layers. The reaction is highly exothermic, heat evolution therefore may become significant because the local increase in temperature contributes to the positive solutal density change in aqueous solutions as a negative thermal density change. When the direction of the overall density change is opposite to that of pure solutal density changes, multicomponent convection is observed where front propagation in both direction differs from the pure reaction-diffusion fronts. [5, 18] In this reactive system, the solutal and thermal density changes have opposite signs, therefore depending on the conditions significant thermal effects lead to cellular structures with entirely different characteristics in both directions. [4, 19, 20]

In this work we are going to characterize experimentally the long time behavior of horizontally propagating vertical chemical fronts developed in Hele-Shaw cells. Scaling laws of the stable patterns will be determined for various chemical compositions and temperature.

\section{EXPERIMENTAL}

We used reagent-grade chemicals (Sigma, Aldrich, Reanal) except for $\mathrm{NaClO}_{2}$, which had been recrystallized twice as described earlier[21]. The solutions, with composition summarized in Table 1, were mixed at room temperature and injected into a $26 \mathrm{~cm}$ long, $1 \mathrm{~mm}$ thick, and $1,1.5,2,2.5,3$, or $4 \mathrm{~cm}$ high reaction vessel with two $8 \mathrm{~mm}$ thick Plexiglas walls. The scheme of the reaction vessel is shown in Fig. 1. Vertical fronts were initiated electrochemically by applying a 3-5 V potential difference between two Pt wires $(0.25 \mathrm{~mm}$ in diameter). We monitored the traveling fronts through an appropriate cut-off filter - to enhance the contrast between reacted and fresh solutions - by a monochrome CCD camera, and the frames were digitized in 2-10 s intervals. The solution densities were determined by an AP Paar DMA 58 digital densitometer within $10^{-5} \mathrm{~g} / \mathrm{cm}^{3}$ precision. 
From the front position, given as the point of inflection in the gray scale values along the direction of propagation ( $\mathrm{x}$ coordinate), the mean front position was determined by averaging it perpendicular to the direction of the propagation (y coordinate). In order to characterize the final front geometry, we calculated the mixing length and the temporal average of the stable front profiles. The mixing length was defined as the standard deviation of the mean front position. The temporal average, determined for the time period where the profiles and hence the mixing length was constant, was the time average of the front profiles with the mean front position shifted to zero.

\section{RESULTS \& DISCUSSION}

In the chlorite-tetrathionate reaction system the products are denser than the reactants, so for a horizontally propagating vertical chemical front the products will sink under the reactants as illustrated in Fig. 2. After a $250 \mathrm{~s}$ - corresponding to a $5 \mathrm{~cm}$ distance traveledtransition period, shown by dotted lines, an asymmetric structure develops which will travel with constant shape and velocity (see the solid lines). This time period can be used to characterize the pattern developed by varying the height of the container. Figure 3 illustrates that the shape is similar in all cases and the mixing length increases on increasing the height of the container. The final geometry is also determined for each case (see Fig. 4) where the standard deviation in each position is negligible.

We have varied the chemical composition to see its effect on the final geometry. Figure 5 illustrates how the mixing length depends on the height of the container. For a given height, the mixing length decreases by increasing the initial concentration of the reactants, i.e., increasing the density difference due to the change of the initial concentration. [5] Since the theoretical analysis predicts a power-law dependence, we have determined both the coefficient and the exponent for each composition. For the lowest concentrations, where $\left[\mathrm{K}_{2} \mathrm{~S}_{4} \mathrm{O}_{6}\right]_{0}=3.75 \mathrm{mM}$ we find that

$$
L_{m} / L^{0}=(0.37 \pm 0.02)\left(L_{y} / L^{0}\right)^{1.20 \pm 0.05}
$$

where the unit length $L^{0}=1 \mathrm{~cm}$. If we consider the system with $\left[\mathrm{K}_{2} \mathrm{~S}_{4} \mathrm{O}_{6}\right]_{0}=5.00 \mathrm{mM}$, we can see that the gradient of this curve is increasing more rapidly and the result of the 
fitting is

$$
L_{m} / L^{0}=(0.23 \pm 0.03)\left(L_{y} / L^{0}\right)^{1.54 \pm 0.12}
$$

The mixing length belonging to the system with $\left[\mathrm{K}_{2} \mathrm{~S}_{4} \mathrm{O}_{6}\right]_{0}=6.25 \mathrm{mM}$ is the lowest and the fitting leads to the equation of

$$
L_{m} / L^{0}=(0.24 \pm 0.04)\left(L_{y} / L^{0}\right)^{1.32 \pm 0.13}
$$

To demonstrate the goodness of the fitting, we scaled the temporal average profiles of the first system with $\left[\mathrm{K}_{2} \mathrm{~S}_{4} \mathrm{O}_{6}\right]_{0}=3.75 \mathrm{mM}$ according to the scaling law of $\xi=x / L_{y}^{1.2}$ and $\eta=y / L_{y}$, where $\xi$ and $\eta$ are the dimensionless space coordinates. The final front profiles fall onto the same curve (see Fig. 6.), indicating that the calculated scaling law describes the experimental observations appropriately.

Considering the mixing length for a given height at the different chemical compositions, one would expect that the increasing solutal density change will lead to greater distortion in the vertical front shape, but it is clearly not the case. We assume that this may be due to thermal effects arising in the system because of the exothermicity of the reaction. The increase in temperature is around $1^{\circ} \mathrm{C}$, which can be eliminated by carrying out the reaction at $3^{\circ} \mathrm{C}$ as shown previously for downward propagating fronts.[20, 22] The mixing length at $3^{\circ} \mathrm{C}$ increases similarly to the one observed at room temperature (see Fig. 7). However, for a given height the mixing length is independent of the chemical composition applied. Only at reactors of 3 and $4 \mathrm{~cm}$ height we observe a slight decrease for the composition with the largest initial concentrations even though the density change almost doubles since it increases from $3.2 \times 10^{-4} \mathrm{~g} / \mathrm{cm}^{3}$ to $5.3 \times 10^{-4} \mathrm{~g} / \mathrm{cm}^{3}$ when the initial concentrations are increased from $\left[\mathrm{K}_{2} \mathrm{~S}_{4} \mathrm{O}_{6}\right]_{0}=3.75 \mathrm{mM}$ to $\left[\mathrm{K}_{2} \mathrm{~S}_{4} \mathrm{O}_{6}\right]_{0}=6.25 \mathrm{mM}$. The power-law dependence is valid at low temperature and the results of the fitting can be given for $\left[\mathrm{K}_{2} \mathrm{~S}_{4} \mathrm{O}_{6}\right]_{0}=3.75$ $\mathrm{mM}$ as

$$
L_{m} / L^{0}=(0.56 \pm 0.06)\left(L_{y} / L^{0}\right)^{1.20 \pm 0.09}
$$

For higher reactant concentrations $\left(\left[\mathrm{K}_{2} \mathrm{~S}_{4} \mathrm{O}_{6}\right]_{0}=5.00 \mathrm{mM}\right)$ where the isothermal density change is greater, the scaling law is

$$
L_{m} / L^{0}=(0.56 \pm 0.05)\left(L_{y} / L^{0}\right)^{1.23 \pm 0.07}
$$

The scaling law for the highest reactant concentration used with $\left[\mathrm{K}_{2} \mathrm{~S}_{4} \mathrm{O}_{6}\right]_{0}=6.25 \mathrm{mM}$ is 
determined as

$$
L_{m} / L^{0}=(0.56 \pm 0.05)\left(L_{y} / L^{0}\right)^{1.14 \pm 0.08} .
$$

It is clear, that both the coefficients and the exponents are the same for all curves within the experimental error. So the fitting of all data to the same power law yields that

$$
L_{m} / L^{0}=(0.56 \pm 0.03)\left(L_{y} / L^{0}\right)^{1.19 \pm 0.04}
$$

which is different from the numerically predicted value of 2 , obtained from a theoretical work based on the model of the iodate-arsenous acid reaction.[15] The two reactions belong to the same class: both are pushed fronts[23, 24] with similar length and time scales under the usual experimental conditions. Although the density change in the course of the iodatearsenous acid reaction has opposite sign, the mixing length is independent of the sign of the Rayleigh number as shown by Rongy et al.[15] The discrepancy between the results of the calculations and the observed scaling law may partly arise from the difference in the kinetics because the quadratic dependence is found in the two-variable model of the iodate-arsenous acid reaction with cubic autocatalysis, while a more complex kinetics drives the chloritetetrathionate reaction. $[8,21]$ Our experimental conditions represent a dimensionless height range almost a magnitude greater than that considered in the calculations. At this height the drag force resulting from the no-slip boundary conditions at top and the bottom has less contribution, therefore the observed smaller exponent in the scaling law upon increasing the height is reasonable.

This work reveals that in the scaling law it is the geometry of the container - the height in this case - that dominantly characterizes the stable vertical patterns propagating horizontally. The same general scenario has been observed in vertically propagating fronts where the final stable singe cell remains unchanged for a wide range of tilt angles even though the initial behavior varies according to the extent of instability.[14] We can also conclude that even in a $1 \mathrm{~mm}$ thin Hele-Shaw cell the thermal effects contribute to the spatiotemporal patterns developed during the front propagation. An increase in the thickness of the solution layer, where heat transfer to the surrounding is not as effective, is therefore anticipated to lead to new type of pattern formation. 


\section{Acknowledgments}

Discussions with Dr. Laurence Rongy and Prof. Anne De Wit are greatfully acknowledged. This work was financially supported by the Hungarian Scientific Research Fund (OTKA K72365) and ESA (C98036). 
[1] I.R. Epstein and J.A. Pojman, An Introduction to Nonlinear Dynamics: Oscillations, Waves, Patterns, and Chaos, Oxford University Press, Oxford, 1998.

[2] I. Nagypál, Gy. Bazsa and I.R. Epstein, J. Am. Chem. Soc. 108, 3635 (1986) .

[3] M. Böckmann and S. C. Müller, Phys. Rev. Lett. 85, 2506 (2000).

[4] T. Bánsági, Jr., D. Horváth, Á. Tóth, J. Yang, S. Kalliadasis and A. De Wit, Phys. Rev. E 68, $055301(\mathrm{R})(2003)$.

[5] T. Bánsági, Jr., D. Horváth and Á. Tóth, Chem. Phys. Lett. 384, 153 (2004).

[6] L. Sebestiková, J.D. D’Hernoncourt, M.J.B. Hauser, S.C. Müller and A. De Wit, Phys. Rev. E 75, 026309 (2007).

[7] A. De Wit, Phys. Rev. Lett. 87, 054502 (2001).

[8] J. Yang, A. D'Onofrio, S. Kalliadasis and A. De Wit, J. Chem. Phys. 117, 9395 (2002).

[9] J. D'Hernoncourt, A. Zebib and A. De Wit, Chaos 17, 013109 (2007).

[10] H.S. Hele-Shaw, Nature 58, 34 (1898).

[11] A. De Wit, Phys. Fluids 16, 163 (2004).

[12] T. Bánsági, Jr., D. Horváth and Á. Tóth, J. Chem. Phys. 121, 11912 (2004).

[13] D. Lima, A. D’Onofrio and A. De Wit, J. Chem. Phys. 124, 014509 (2006).

[14] T. Tóth, D. Horváth and Á. Tóth, J. Chem. Phys. 128, 144509 (2008).

[15] L. Rongy, N. Goyal, E. Meiburg and A. De Wit, J. Chem. Phys. 127, 114710 (2007).

[16] I. Nagypál and I.R. Epstein, J. Phys. Chem. 90, 6285 (1986).

[17] A.K. Horváth, J. Phys. Chem. A 109, 5124 (2005).

[18] J.A. Pojman, A. Komlósi and I.P. Nagy, J. Phys. Chem. 100, 16209 (1996).

[19] S. Kalliadasis, J. Yang and A. De Wit, Phys. Fluids 16, 1395 (2004).

[20] T. Tóth, D. Horváth and Á. Tóth, Chem. Phys. Lett. 442, 289 (2007).

[21] Á. Tóth, D. Horváth and A. Siska, J. Chem. Soc., Faraday Trans. 93, 73 (1997).

[22] G.G. Casado, L. Tofaletti, D. Müller and A. D'Onofrio, J. Chem. Phys. 126, 114502 (2007).

[23] W. van Saarloos, Phys. Rep. 386, 29 (2003).

[24] D. Lima, W. van Saarloos and A. De Wit, Physica D 218, 158 (2006). 
TABLE I: Composition of reactant solution

\begin{tabular}{ll}
\hline$\left[\mathrm{K}_{2} \mathrm{~S}_{4} \mathrm{O}_{6}\right] / \mathrm{mM}$ & $3.75-6.25$ \\
{$\left[\mathrm{NaClO}_{2}\right] / \mathrm{mM}$} & $15-25$ \\
{$[\mathrm{NaOH}] / \mathrm{mM}$} & $2.5-5$ \\
{$[$ Congo red $] / \mathrm{mM}$} & 0.574 \\
\hline
\end{tabular}


Fig. 1 Scheme of the Hele-Shaw cell.

Fig. 2 Front position for $\left[\mathrm{K}_{2} \mathrm{~S}_{4} \mathrm{O}_{6}\right]_{0}=3.75 \mathrm{mM},\left[\mathrm{NaClO}_{2}\right]_{0}=15 \mathrm{mM}$, and $[\mathrm{NaOH}]_{0}=$ $2.5 \mathrm{mM}$ at $2 \mathrm{~cm}$ reaction vessel height. The dotted lines represent the front evolution from $50 \mathrm{~s}$ to $250 \mathrm{~s}$ after the front initiation. The solid lines indicate the stable patterns.

Fig. 3 Images of fronts at $25{ }^{\circ} \mathrm{C}$ for $\left[\mathrm{K}_{2} \mathrm{~S}_{4} \mathrm{O}_{6}\right]_{0}=5.00 \mathrm{mM},\left[\mathrm{NaClO}_{2}\right]_{0}=20 \mathrm{mM}$, and $[\mathrm{NaOH}]_{0}=2.5 \mathrm{mM}$ at $1 \mathrm{~mm}$ gapwidth and $1 \mathrm{~cm}$ (a), $2 \mathrm{~cm}$ (b) and $4 \mathrm{~cm}$ (c) height. Darker regions represent the denser product solution and lighter ones the reactant.

Fig. 4 Temporal average profile of stable patterns with the composition $\left[\mathrm{K}_{2} \mathrm{~S}_{4} \mathrm{O}_{6}\right]_{0}=$ $3.75 \mathrm{mM},\left[\mathrm{NaClO}_{2}\right]_{0}=15 \mathrm{mM}$ and $[\mathrm{NaOH}]_{0}=2.5 \mathrm{mM}$ at $2 \mathrm{~cm}$ Hele-Shaw cell height.

Fig. 5 The mixing length $L_{m}$ as a function of the height of the container $L_{y}$ at room temperature. The measurements are shown by symbols: for $\left[\mathrm{K}_{2} \mathrm{~S}_{4} \mathrm{O}_{6}\right]_{0}=3.75$ $\mathrm{mM}(\mathrm{\circ})$, for $\left[\mathrm{K}_{2} \mathrm{~S}_{4} \mathrm{O}_{6}\right]_{0}=5.00 \mathrm{mM}(\triangle)$ and for $\left[\mathrm{K}_{2} \mathrm{~S}_{4} \mathrm{O}_{6}\right]_{0}=6.25 \mathrm{mM}(\square)$. The solid line shows the fitting for the system with solution composition of $\left[\mathrm{K}_{2} \mathrm{~S}_{4} \mathrm{O}_{6}\right]_{0}$ $=3.75 \mathrm{mM}$, the dotted line for $\left[\mathrm{K}_{2} \mathrm{~S}_{4} \mathrm{O}_{6}\right]_{0}=5.00 \mathrm{mM}$, and the dashed line for $\left[\mathrm{K}_{2} \mathrm{~S}_{4} \mathrm{O}_{6}\right]_{0}=6.25 \mathrm{mM}$.

Fig. 6 Overlay of normalized profiles for the stable patterns with the same composition as in Fig. 4. The height of the Hele-Shaw cell: $1.0 \mathrm{~cm}$ (solid line), $1.5 \mathrm{~cm}$ (dotted line), $2.0 \mathrm{~cm}$ (dashed line), $2.5 \mathrm{~cm}$ (dashed-dotted line), $3.0 \mathrm{~cm}$ (dashed-dasheddotted line) and $4.0 \mathrm{~cm}$ (dotted-dotted-dashed line).

Fig. 7 The mixing length $L_{m}$ as a function of the height of the container $L_{y}$ at $3{ }^{\circ} \mathrm{C}$. The measurements are shown by symbols: for $\left[\mathrm{K}_{2} \mathrm{~S}_{4} \mathrm{O}_{6}\right]_{0}=3.75 \mathrm{mM}(\mathrm{o})$, for $\left[\mathrm{K}_{2} \mathrm{~S}_{4} \mathrm{O}_{6}\right]_{0}=5.00 \mathrm{mM}(\triangle)$ and for $\left[\mathrm{K}_{2} \mathrm{~S}_{4} \mathrm{O}_{6}\right]_{0}=6.25 \mathrm{mM}(\square)$. The dotted line shows the result of fitting of solution composition with $\left[\mathrm{K}_{2} \mathrm{~S}_{4} \mathrm{O}_{6}\right]_{0}=3.75 \mathrm{mM}$, the dashed-dotted line that with $\left[\mathrm{K}_{2} \mathrm{~S}_{4} \mathrm{O}_{6}\right]_{0}=5.00 \mathrm{mM}$, and the dashed line that with $\left[\mathrm{K}_{2} \mathrm{~S}_{4} \mathrm{O}_{6}\right]_{0}=6.25 \mathrm{mM}$. The solid line corresponds to the overall fitting of every data. 


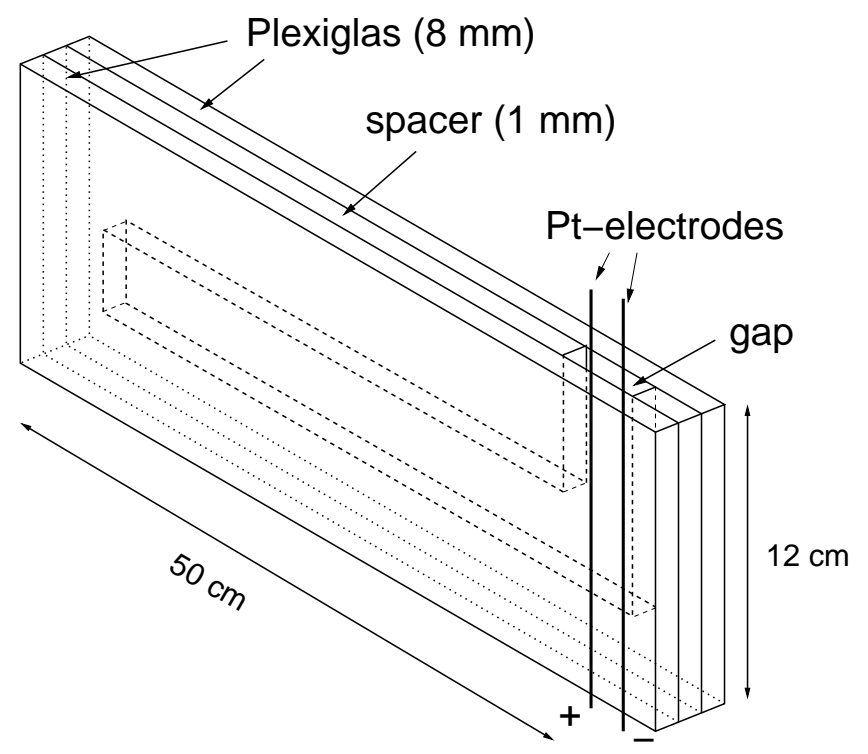

FIG. 1: T. Tóth ... Phys. Rev. E 


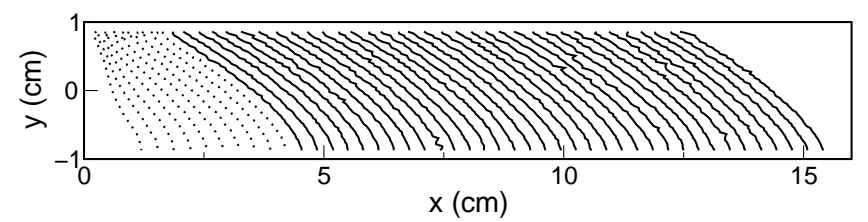

FIG. 2: T. Tóth ... Phys. Rev. E 
(a)

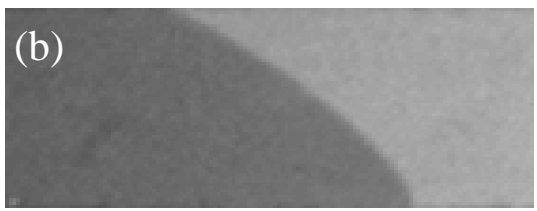

(c)

$1 \mathrm{~cm}$

FIG. 3: T. Tóth ... Phys. Rev. E 


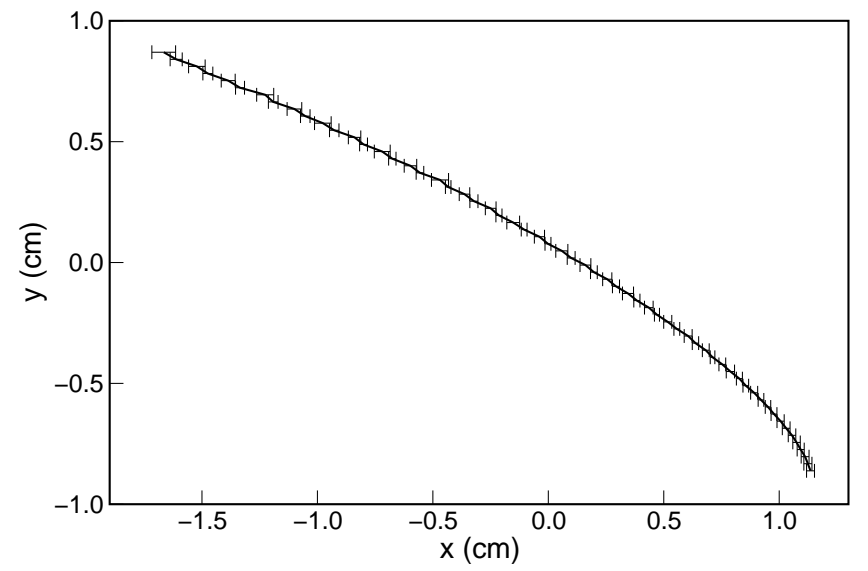

FIG. 4: T. Tóth ... Phys. Rev. E 


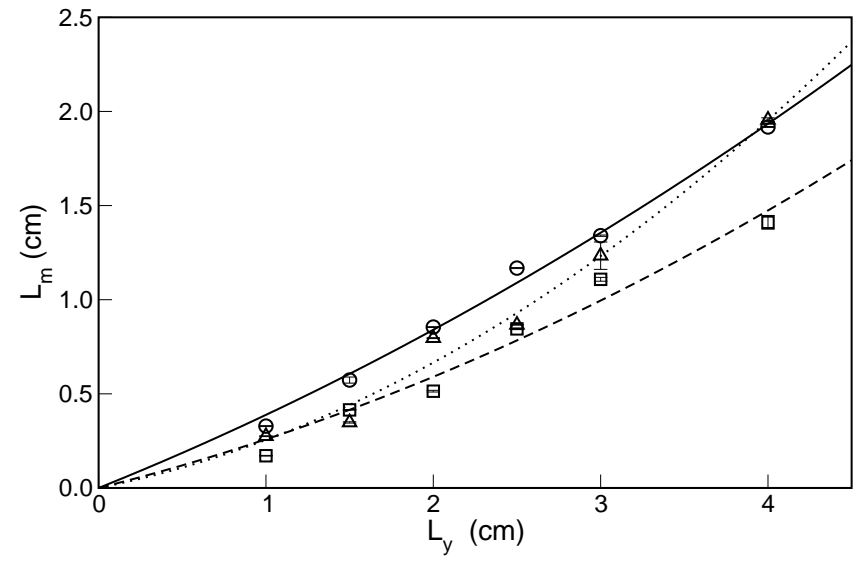

FIG. 5: T. Tóth ... Phys. Rev. E 


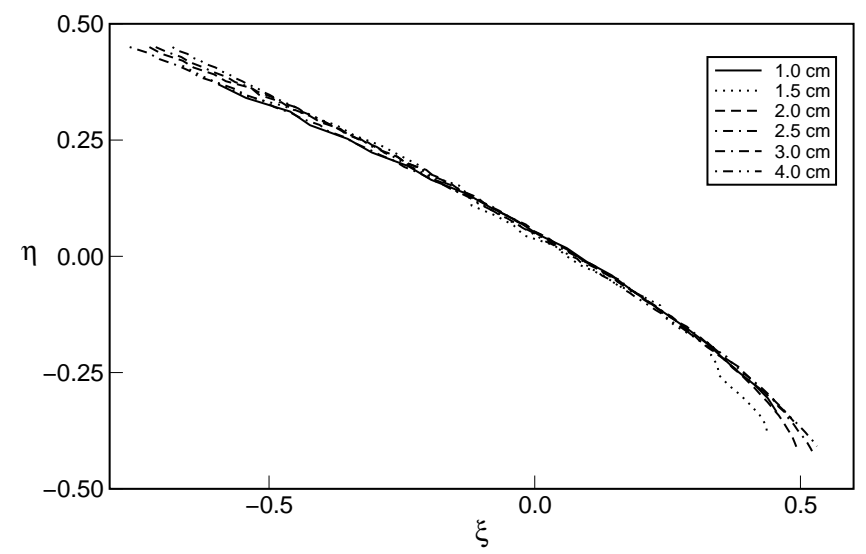

FIG. 6: T. Tóth ... Phys. Rev. E 


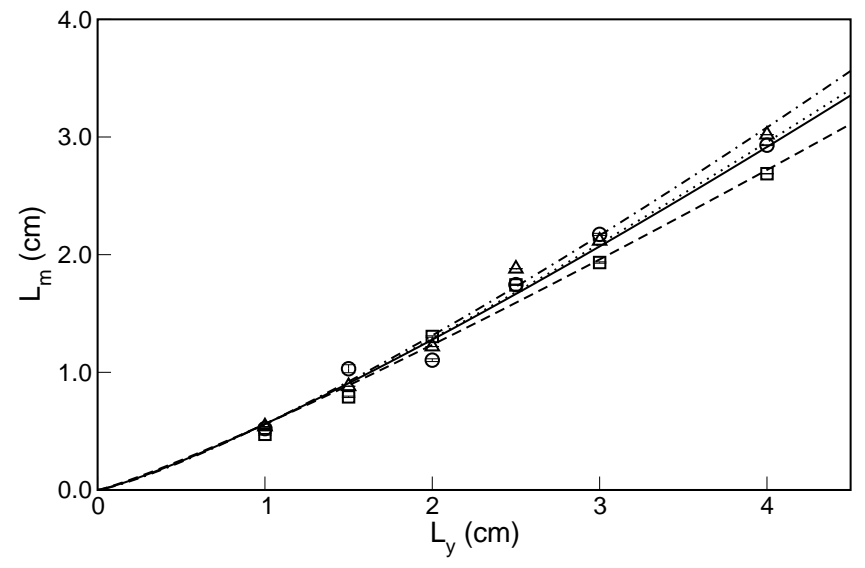

FIG. 7: T. Tóth ... Phys. Rev. E 